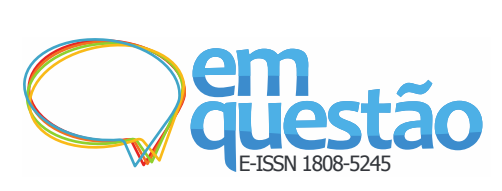

\title{
Contribuições da Ciência da Informação para a cidadania digital no Brasil: a participação social em questão
}

\author{
Sandryne Bernardino Barreto Januário \\ Mestre; Tribunal de Justiça de Pernambuco, Recife, PE, Brasil; \\ sandrynebarreto@gmail.com \\ Renato Fernandes Correa \\ Doutor; Universidade Federal de Pernambuco, Recife, PE, Brasil; \\ renato.correa@ufpe.br
}

\begin{abstract}
Resumo: Apresenta levantamento e discussão de trabalhos brasileiros sobre a cidadania digital na área da Ciência da Informação, com foco na participação social. Trata-se de pesquisa bibliográfica, exploratória e descritiva, pautada na análise de conteúdo das publicações selecionadas. A partir da pesquisa bibliográfica foram levantados onze trabalhos publicados nos últimos dez anos em periódicos científicos, eventos acadêmicos ou programas de pós-graduação em Ciência da Informação, diretamente relacionados à temática em questão. São sintetizados e apresentados os objetos, objetivos e contribuições de cada trabalho. Em seguida, apresenta-se e discute-se um quadro com o resumo dos estudos, incluindo os aspectos de cidadania digital identificados em cada trabalho. Como resultados, observou-se que a maior parte das pesquisas apontou problemáticas que impactam diretamente no exercício da cidadania digital. Isso porque, segundo os pesquisadores, parte das iniciativas nesse tema está cercada de um discurso de participação sem efeitos práticos, com pouca ou nenhuma influência no processo de decisão política. Por outro lado, também foram apresentados estudos na área que demonstraram a consolidação e a tendência do uso dos Dados Governamentais Abertos para um novo modelo de governança digital, o que representa um grande avanço para a cidadania digital no Brasil.
\end{abstract}

Palavras-chave: Cidadania Digital. Participação social. Ciência da Informação. Brasil.

\section{Introdução}

No auge de uma grave crise institucional no Brasil, iniciada em meados de 2014, em que o nosso modelo democrático se apresenta tão enfraquecido e desacreditado, falar sobre cidadania digital e democracia digital num artigo científico parece ser um grande desafio. E sim, ele é tão vasto quanto instigante, justamente porque as formas de fazer democracia e de exercer a cidadania estão 
sendo reinventadas e ressignificadas em tempo real, sem fronteiras e mutáveis a cada nova possibilidade ou plataforma digital disponível, perfazendo assim uma cidadania digital.

Acredita-se que o conceito da cidadania em si está em profunda evolução, o que representa uma série de desafios que exigem a sua redefinição. Questões como a inclusão e a exclusão digital, a segurança da informação, a privacidade dos dados, os direitos e os deveres dos cidadãos exercidos em meio digital e o impacto cultural disso tudo na Sociedade de Informação são centrais para a compreensão das mudanças estruturais em curso. Estendendo isso para o contexto da cidadania digital, para além dos desafios citados, ela é uma temática ainda recente, em contínuo desenvolvimento e que somente há poucos anos começou a despertar a atenção da comunidade acadêmica. Por isso, nesse estudo, o foco será quanto aos direitos e deveres cívicos do cidadão em meio digital.

A definição de cidadania digital que melhor se aplica a este estudo é a dos professores Ângela Grossi de Carvalho e Marcos Américo (2014), do Programa de Pós-Graduação em Ciência da Informação da Universidade Estadual Paulista Júlio de Mesquita Filho (UNESP) e do Programa de PósGraduação em Mídia e Tecnologia (PPGMiT), respectivamente. Eles acreditam que a cidadania digital é a ampliação dos direitos já conquistados nos campos social, político, econômico e cultural para as redes digitais, especialmente para aquelas que utilizam as Tecnologias de Informação e Comunicação - TICs (CARVALHO; AMÉRICO, 2014).

Sendo assim, o objetivo desse estudo é analisar as publicações científicas brasileiras sobre cidadania digital na área da Ciência da Informação (CI) com foco na participação social do cidadão, buscando explicitar as contribuições da CI para o desenvolvimento da cidadania digital no Brasil.

Diante desse objetivo, o desafio é trilhar caminhos que busquem discutir o papel das TICs no fortalecimento das práticas democráticas, ampliando as possibilidades de exercício da cidadania e da democracia em ambientes digitais. Dado que num contexto de questionamento - que não é recente - dos modelos políticos tradicionais, as novas tecnologias digitais começam a ser apropriadas 
por representantes políticos e membros da sociedade civil na tentativa de modificar o cenário político (CASTELLS, 2001). Assim, vinte anos após a disseminação da Internet em todo o mundo, sem esquecer a desigualdade que há em torno disso, o surgimento de diferentes formas de organização política por meio do uso de ferramentas online tem sido cada vez mais estudado nas mais diversas áreas do conhecimento científico.

Nessa perspectiva, a Ciência da Informação tem um papel fundamental, uma vez que a informação e tudo o que ela envolve, tal como o acesso, o uso (e reuso), a organização, a recuperação e o compartilhamento da informação, especialmente da informação pública, são aspectos basilares para a promoção da cidadania digital. Além disso, a responsabilidade social é uma das principais funções da CI, pois é a partir dela que se busca suprir demandas informacionais, investigar problemas e explorar temas relacionados com o fenômeno informacional ou comunicacional perceptível e cognoscível aos indivíduos (GARCIA; TARGINO; DANTAS, 2012).

Adicionalmente, este artigo se justifica para além do caráter social da Ciência da Informação, mas também em conformidade com a sua característica interdisciplinar. Nesse aspecto, Araújo (2003) atenta para o fato de que, enquanto a CI não for percebida com ênfase na conotação social, suas contribuições por meio da produção intelectual ou científica não terão impacto na conjuntura coletiva.

Assim, faz-se necessário compreender como CI está atuando nesse cenário tão contemporâneo e social, de modo a contribuir com o desenvolvimento da cidadania digital no Brasil.

Este trabalho está estruturado como descrito a seguir. Na seção 2 é desenvolvida uma breve fundamentação teórica que trata de aspectos da cidadania digital e da participação social na web enquanto objeto de estudo da CI. Em seguida, na seção 3 serão apresentados os procedimentos metodológicos empregados no levantamento e discussão dos trabalhos em CI dentro da temática da cidadania digital. A seção 4 apresenta e discute as contribuições da Ciência da Informação à cidadania digital no Brasil e por fim, as considerações finais do estudo são apresentadas na seção 5 . 


\section{Fundamentação teórica}

Thomas Humphrey Marshall, sociólogo britânico do início do século XX, afirmou que a ideia de cidadania surgiu na Inglaterra, antes mesmo da Revolução Industrial. Na década de 1950, o autor desenvolveu a distinção entre as várias dimensões que envolvem a cidadania, classificando-as por meio dos direitos civis, políticos e sociais. Primeiro vieram os direitos civis, no século XVIII. Depois, no século XIX, surgiram os direitos políticos e finalmente, os direitos sociais foram conquistados no século XX (CARVALHO, 2008).

José Murilo de Carvalho (2008), historiador brasileiro e autoridade nos estudos de cidadania no país, afirma que um cidadão só seria pleno se fosse titular dos três direitos classificados por Marshall e esclareceu os conceitos relativos a cada um. Para Carvalho (2008), os direitos civis são os direitos fundamentais à vida, à liberdade, à propriedade, à igualdade perante a lei. Já os direitos políticos se referem à participação do cidadão no governo enquanto parte da sociedade (CARVALHO, 2008). Para o autor, seu exercício é limitado a uma parcela da população e consiste na capacidade de, entre outros aspectos, fazer demonstrações políticas, organizar partidos, de votar, de ser votado (CARVALHO, 2008). Por fim, conceituou os direitos sociais como aqueles que garantem a participação na riqueza coletiva. Neles se incluem o direito à educação, ao trabalho, ao salário justo, à saúde, à aposentadoria (CARVALHO, 2008).

Já Frade (2002) discute o conceito de cidadania à luz das mudanças e exigências do mundo contemporâneo. Para o autor, o conceito é mutável desde os primórdios da sociedade organizada, mas nas últimas décadas essa variação se acelerou em ritmos alucinantes (FRADE, 2002). A intensificação e ampliação da globalização da política, da economia, da quebra de fronteiras na disseminação de culturas, assim como a explosão e mercantilização da informação condicionaram o exercício da cidadania plena ao alcance de novos patamares de riqueza, educação e acesso a serviços e produtos (FRADE, 2002).

Isso posto, é importante refletir não apenas sobre o que é a cidadania hoje, no contexto mutável e sem barreiras físicas no qual vivemos graças à 
Internet, mas como exercer essa cidadania na conjuntura atual. Isso porque a cidadania é um direito que não necessariamente deve ser dado pelo governo, até porque ele possivelmente não seria entregue em sua completude ou viria sem interesse. Uma sociedade educada sobre seus direitos é o que proporciona à cidadania ser verdadeiramente construída e apropriada, e a informação é fundamental nesse processo. Para isso, é necessário incentivar o interesse no cidadão, inclusive desde a infância, em se engajar com o coletivo, partindo de questões relacionadas à sua casa, à sua rua, à sua escola, ao seu bairro, ao seu país, para acessar e usar a informação ao seu favor e a favor dos outros. De acordo com Rocha (2000), essa conscientização é um processo que permite ao homem compreender a realidade que o cerca, como ela se estrutura e como reagir a essa realidade, assumindo o seu destino e o dos seus semelhantes com autonomia, buscando melhores condições de vida. Jambeiro, Sobreira e Macambira (2011) corroboram nesse entendimento ao afirmar que é cada vez maior a crença de que a participação de cidadãos ativos e informados é a chave para a construção de uma sociedade efetivamente democrática.

E hoje é inquestionável a importância dos processos políticos democráticos para a consolidação da cidadania. Afinal, bem como afirmou Ribeiro (2003), "Democracia e cidadania tornaram-se um binômio inseparável, que tem como tônica a igualdade social, a igualdade de direitos." (RIBEIRO, 2003, p. 12). Num contexto mais específico, Gomes (2005) acredita que a questão central da democracia é a decisão política e o seu problema principal consiste em como incrementar os níveis de participação civil nas decisões relacionadas à gestão pública.

É nesse contexto de participação social por meio da internet que os conceitos de cidadania digital e democracia digital estão relacionados com o conceito de governo eletrônico, que é um dos instrumentos proporcionados pelas novas TICs para a promoção da cidadania e para a garantia da democracia. $\mathrm{O}$ governo eletrônico ou eletronic governament (e-gov) surgiu a partir da segunda metade da década de 1990, nos Estados Unidos (ARAÚJO; CARDOSO, 2006).

Na Ciência da Informação, segundo Parra Filho e Martins (2017), é possível identificar nos últimos anos, uma mudança conceitual quanto ao debate 
do governo eletrônico para governança eletrônica, o e-governança. Ou seja, a governança eletrônica passa de uma das três dimensões ou perspectivas do governo eletrônico para uma nova terminologia conceitual. É por isso que Cunha e Miranda (2013) enfatizam que o conceito de e-governança "[...] pode e deve incluir a melhoria $[\ldots]$ no exercício de uma nova forma e possibilidade de governar, com a participação de uma ampla rede de atores." (CUNHA; MIRANDA, 2013, p. 547). Em debate, agora, estariam as diferentes formas de utilizar as ferramentas e plataformas digitais e da Internet, por parte dos governos, para permitir a participação dos cidadãos.

Percebe-se assim o impacto que a Internet promoveu na sociedade ao constituir-se como um espaço de interação social e econômica e que vem permitindo à cidadania e à democracia que sejam exercidas por meio do ciberespaço a nível mundial, mas isso não extingue as formas tradicionais de se fazer democracia e de ser exercer a cidadania. A cidadania e a democracia digitais apenas favorecem este processo por meio do uso de ferramentas tecnológicas que abrangem ações, iniciativas e mobilizações numa escala ampla, global. Ou seja, esta forma de exercer a cidadania e a democracia está intimamente ligada ao ciberespaço, pois “[...] implicam naquilo que a humanidade tem de mais essencial: a aspiração à liberdade e à potência criativa da inteligência criativa." (LÉVY, 2002, p. 125).

Por isso que a cidadania digital e a democracia digital tendem a continuar crescendo diante do contínuo desenvolvimento de plataformas digitais de informação pública, especialmente graças à liberdade individual e coletiva da sociedade quanto à produção, distribuição e consumo de tais informações. Além disso, o debate e conscientização social acerca da importância da cidadania digital e da democracia digital tem permitido o surgimento do debate acerca da participação social do cidadão nos mais diversos ambientes digitais.

A participação social relacionada às questões da administração pública é uma conquista legal recente, pois se deu com o marco da Constituição de 1988. Mas foi em meados da década de 1990, por causa da Internet, que TICs começaram a ser utilizadas para permitir a participação dos cidadãos em diferentes etapas dos processos decisórios, o que passou a ser chamado por 
participação política online ou e-participação. (PARRA FILHO; MARTINS, 2017).

E é neste tipo de política, uma política participativa por meio do uso da Internet, que a democracia digital está inserida, uma vez que ela ultrapassa os limites do Estado numa concepção de ciberespaço, atuando num ambiente desterritorializado, sem uma aparente hierarquia e oportunizando à sociedade estabelecer os mais diversos tipos de relações entre si. Segundo Santos (2013), a democracia digital se organiza em aspectos relacionados a promover uma informação específica, direcionada aos indivíduos, assim como o campo filosófico da Ciência da Informação, ao proporcionar um processo de reflexão, debate, discussão, deliberação e tomada de decisão política, nesse contexto visando uma efetiva participação social.

Ainda segundo Santos (2013), há três discursos distintos referentes à democracia digital na perspectiva da participação política e social na Internet. O primeiro discurso diz respeito à dimensão informacional, ou seja, é o cidadão bem informado numa democracia transparente. $\mathrm{O}$ segundo discurso se refere à Internet como um espaço público de discussão revitalizado para exercer a democracia, ou seja, como um instrumento para estimular a discussão entre os cidadãos e os representantes políticos. Já o terceiro discurso é quanto à participação dos cidadãos nas decisões políticas, na qual os recursos e ferramentas digitais podem incidir no processo de intervenção direta.

É nesse contexto que Santos (2013) acredita que:

O debate democrático pressupõe a liberdade de expressão dos indivíduos e a igualdade de condições, incluindo os aspectos relacionados à democracia (isonomia social no acesso aos avanços tecnológicos) e uma interação que transcenda o espaço geográfico, social e cultural; um ambiente para apresentar e discutir diferentes opiniões, convergindo os vínculos sociais ou identidades temáticas para ampliar as diversas perspectivas (visões) concernentes a determinados assuntos. (SANTOS, 2013, p. 199).

Nesse sentido, Vedel (2003) destaca que a Internet extrapola o ambiente comunicacional entre governantes e governados para constituir um canal de expressão cívico. 
Já Maia (2008) acrescenta outra visão ao afirmar que as tecnologias apresentam duas dimensões não excludentes entre si no processo democrático: a primeira confere possibilidades ideais para a comunicação democrática, ou seja, uma participação descentralizada, mas que pode sustentar possíveis concentrações de poder. A segunda dimensão afirma que, para revigorar a democracia, as estruturas comunicacionais ou as instituições destinadas à participação social são insuficientes, mas o interesse em participar, bem como a motivação e a disponibilidade dos indivíduos se engajarem em debates constituem princípios norteadores do regime democrático.

É por isso que as aplicações tecnológicas, independentemente de contribuir ou dificultar o processo democrático, devem partir do princípio associativo entre os procedimentos comunicacionais dos indivíduos e os respectivos contextos sociais e históricos em que eles estão inseridos (SANTOS, 2011). É nesse contexto de participação que a seguir serão apresentados os procedimentos metodológicos e as contribuições da CI para a cidadania digital, com foco na participação social do cidadão.

\section{Metodologia}

A pesquisa tem como objetivo analisar as publicações científicas brasileiras na área da Ciência da Informação sobre cidadania digital com foco na participação social do cidadão. Ela se configura de natureza qualiquantitativa e quanto aos objetivos, a pesquisa se configura inicialmente como exploratória e, em seguida, descritiva. Já quanto aos meios ou procedimentos utilizados na pesquisa para coleta dos dados, eles se deram por meio da pesquisa bibliográfica.

Neste estudo, a pesquisa bibliográfica foi realizada por meio de buscas na Base de Dados em Ciência da Informação (BRAPCI), na Biblioteca Digital de Teses e Dissertações (BDTD) do Instituto Brasileiro de Ciência e Tecnologia (IBICT) e nos anais do Encontro Nacional de Pesquisa em Ciência da Informação (ENANCIB). O levantamento dos trabalhos publicados foi realizado entre os meses de agosto de 2018 até dezembro de 2018. 
A pesquisa utilizou como filtro de período as publicações realizadas entre os anos de 2008 e 2018 e buscou por meio dos termos indexadores cidadania digital, cidadão, participação social, tecnologia cívica e democracia digital. Para subsidiar a análise dos dados coletados foram utilizadas técnicas de análise de conteúdo para possibilitar uma análise mais abrangente dos trabalhos científicos, na perspectiva de apresentar brevemente os objetos, objetivos e atividades desenvolvidas em cada uma dessas pesquisas para, em seguida, pontuar as diferentes perspectivas dos estudos desenvolvidos.

\section{Análise dos resultados}

Nesta seção, apresenta-se o resultado da análise dos trabalhos da literatura nacional de Ciência da Informação que trazem contribuições para a consolidação da cidadania digital no Brasil na perspectiva de participação social.

Na primeira subseção são discutidos cada um dos trabalhos em ordem cronológica crescente. Na segunda seção, apresenta-se o resultado da análise de conteúdo sobre os resumos informativos gerados de cada trabalho, visando correlacioná-los entre si e com a temática cidadania digital.

\subsection{Contribuições da Ciência da Informação à Cidadania Digital no Brasil}

Por ser uma ciência, dentre outras características, interdisciplinar, tecnológica e social, percebe-se uma produção constante de pesquisas relacionadas à cidadania digital e à democracia na web na literatura brasileira de Ciência da Informação. Isso porque a informação e tudo o que ela envolve, tal como o acesso, o uso, a organização, a recuperação e o compartilhamento são aspectos basilares para a promoção da cidadania digital e para uma efetiva democracia digital.

Nesse contexto, após uma revisão de literatura na CI sobre essa temática, onze pesquisas publicadas na área nos últimos dez anos foram selecionadas. Esse quantitativo não está relacionado a nenhum critério específico que não seja a temática dos estudos estarem diretamente relacionados à cidadania digital, com foco aplicado na participação social do cidadão. O recorte temporal se deu 
na perspectiva de ter uma análise mais próxima da realidade atual e do exercício da cidadania digital no Brasil neste período.

A seguir, apresentam-se brevemente os objetos, objetivos e atividades desenvolvidas em cada um desses estudos, sendo os trabalhos descritos seguindo a ordem crescente do ano de publicação.

Em 2009, Carvalho e Santos (2009) publicaram um artigo cujo objetivo foi explorar como se processa a gestão da informação em órgãos ligados ao governo federal e, especialmente, em programas de inclusão digital, bem como conceituar gestão da informação, gestão pública da informação e política de informação. Para tanto, as autoras (CARVALHO; SANTOS, 2009) buscaram por meio de uma pesquisa bibliográfica e documental apontar os principais conceitos acerca da cidadania digital e a distribuição da informação nos projetos governamentais. Segundo elas, as iniciativas apresentadas são importantes, mas não suficientes e por isso se fazem necessárias muitas outras ações que possam chegar a todos os brasileiros, uma vez que as disparidades existentes são destacadas pela falta de oportunidade na sociedade da informação (CARVALHO; SANTOS, 2009). Carvalho e Santos (2009) acreditam, por fim, que é dever do Estado buscar formas de suprir as deficiências, fazendo com que todo cidadão brasileiro tenha oportunidades iguais, aproveitando a informação e conhecimento construídos e mediados no espaço digital.

Jambeiro, Sobreira e Macambira (2011) apresentaram, num congresso científico, um artigo com a análise dos Websites das Câmaras de Vereadores e Prefeituras das 26 Capitais dos Estados brasileiros, visando verificar se e como essas plataformas interagem com os cidadãos. Para tanto foram investigados: (1) o Design Estrutural; (2) a disponibilização de ferramentas de participação cívica; e (3) o fornecimento de informações que permitissem aos cidadãos conhecer e acompanhar as ações e projetos do poder público municipal. Os resultados mostraram que as Capitais estão longe de aproveitar as potencialidades que a Web oferece para a criação de serviços informacionais capazes de ampliar o acesso do cidadão às informações governamentais e fazêlos participar da gestão e do controle das ações das Municipalidades, uma vez 
que possuem baixa qualidade informacional nas três variáveis selecionadas para a análise.

A pesquisa de dissertação de Santos (2011) investigou como os websites dos deputados da Assembleia Legislativa da Bahia - ALBA - condicionam a participação política a partir de canais interativos para a consecução de informação pública em rede. O objetivo principal do estudo foi analisar as condições de participação política nos sítios parlamentares (SANTOS, 2011). A dissertação se caracterizou como uma pesquisa descritiva, uma vez que o investigador procurou descrever as características dos websites dos deputados (população ou fenômeno), incluindo na seção metodológica as técnicas e instrumentos de coleta de dados (observação, entrevistas e formulário de pesquisa) (SANTOS, 2011). A conclusão evidenciou que a disponibilidade de dispositivos dos websites orientados à interatividade entre agentes governamentais e os cidadãos não garante que as demandas sejam respondidas e as sugestões efetivadas (SANTOS, 2011). A pesquisa confirmou que estes sítios, e como consequência, os deputados e as Assessorias, não apresentaram indícios administrativos e estruturais dos Gabinetes para responder às demandas ou sugestões dos cidadãos (SANTOS, 2011).

Azevedo (2012), em seu artigo intitulado Algumas considerações acerca de uma democracia direta eletrônica, apresentou a experiência de democracia eletrônica do partido Demoex, que foi uma tentativa de viabilizar, por meio das TICs, uma maior participação dos cidadãos nas decisões políticas, implementada na cidade de Vallentuna, na Suécia. Em Azevedo (2012) foram discutidas também iniciativas existentes no Brasil, explorando as funcionalidades dos feedbacks negativos e positivos para viabilizar a criação de espaços democráticos na Web. O estudo concluiu que os espaços ou interfaces de democracia digital, assim como os voltados para a transparência pública, precisam reconhecer e se adaptar às necessidades e particularidades do cidadão, devendo ser pensados e criados com foco nesse usuário final. E que embora a eficácia da democracia digital não possa ser facilmente aferida para o bem-estar social, teoricamente, ela dá ao povo uma nova chance de se aproximar da política e assim, do controle da sua própria vida. 
Em 2014, Cerquinho, Tavares e De Paula (2014) publicaram um artigo cujo objetivo foi observar e analisar o Fórum Eletrônico do Estado de Minas Gerais, intitulado Movimento Minas, para verificar quais as principais conversas que foram propostas pelos cidadãos e se o governo concretizou as proposições virtuais. Realizou-se uma pesquisa qualitativa por meio da netnografia e os resultados encontrados sugeriram que as ações provenientes do movimento e concretizadas pelo Estado de Minas não estavam relacionadas às propostas e sugestões indicadas pelos cidadãos e usuários na plataforma (CERQUINHO; TAVARES; DE PAULA, 2014). Tal resultado colocou em questão se o governo está de fato trabalhando em conjunto com as pessoas ou se a plataforma está cercada de um discurso de participação, sem efeitos práticos.

Moreira (2015) teve como objetivo, em sua pesquisa de mestrado, traçar um panorama sobre como a sociedade brasileira está utilizando os Dados Governamentais Abertos (DGA), a partir do estudo dos aplicativos gerados. A identificação dos aplicativos que utilizaram os DGA no Brasil foi realizada a partir de informações oficiais do Portal Brasileiro de Dados Abertos e de informações extraídas de notícias sobre DGA no Brasil arquivadas no Observatório de Gestão da Informação, a partir do Alerta Google (MOREIRA, 2015). O estudo apresentou resultados que demonstraram a consolidação e a tendência de ampliação do uso dos DGA, apontando um modelo de governança caracterizado pelo envolvimento de atores estatais e não estatais, pela efetiva utilização das TIC, pela transparência, pelo direito de acesso à informação, e pelo controle e participação social.

A pesquisa de mestrado de Brisola (2016) procurou traçar uma linha teórica para a discussão da competência crítica em informação voltada ao projeto de uma cidadania ampliada na ágora digital, percorrendo os conceitos envolvidos neste assunto. O objetivo principal foi pensar em como despertar o gosto pela informação e pela construção do conhecimento a fim de estimular o exercício de uma cidadania participativa (BRISOLA, 2016). A metodologia empregada foi a pesquisa bibliográfica, no intuito de percorrer um caminho para que tais análises possibilitassem a realização de posteriores estudos de campo sob estas óticas (BRISOLA, 2016). A autora concluiu que é um longo caminho a 
trilhar, mas necessário à CI e de sua responsabilidade, já que se trata de colaborar com a formação do conhecimento no cidadão que convive neste cibermundo contemporâneo (BRISOLA, 2016).

O artigo de Barros (2016) apresentou uma análise de três plataformas de consulta pública que foram desenvolvidas durante o processo de elaboração do Marco Civil da Internet (MCI). O objetivo foi avaliar, a partir de critérios da literatura de democracia digital, como as características das plataformas modelaram o processo de participação e quais lições poderiam ser aprendidas com esse processo (BARROS, 2016). Os critérios utilizados foram: (1) inclusividade e pluralismo; (2) recursos epistêmicos; (3) forma e empoderamento da participação; (4) governo da iniciativa: termos de uso, identificação e moderação (BARROS, 2016). O autor concluiu que há uma falta de um procedimento padrão para esse tipo de consulta, o que torna o mecanismo vulnerável à vontade dos gestores e potencialmente alvo de desconfiança por parte do público, e que a padronização das consultas poderia beneficiar o governo e a sociedade (BARROS, 2016).

A dissertação de Ribeiro (2017) teve o objetivo de identificar o estado da arte sobre a participação política e aprofundar o tema por meio de casos de iniciativas online criadas para permitir e/ou estimular a participação do cidadão nas questões políticas, no Brasil e no mundo. O principal método utilizado foi a revisão sistemática da literatura (RSL) e os resultados foram analisados de acordo com as características dos artigos e das plataformas encontradas nos estudos de casos, com as suas vantagens e desvantagens para a participação política do cidadão. A autora concluiu que a maioria das plataformas online de participação política é representada por portais governamentais que promovem um fluxo de informação com alguma possibilidade de interação e discussão entre cidadãos e governantes, mas pouca ou nenhuma influência no processo de decisão política, especialmente nos casos do Brasil (RIBEIRO, 2017).

Parra Filho e Martins (2017) publicaram um artigo cujo objetivo foi realizar um balanço do cenário da época quanto ao uso de tecnologias por parte dos governos, especialmente quanto às inovações produzidas na última década no Poder Executivo Federal brasileiro. A análise dessas inovações se deu em 
torno do debate sobre o que eles chamaram de três dilemas: a inclusão digital, a manipulação política e a governança digital (PARRA FILHO; MARTINS, 2017). O estudo apresentou ainda relatos das últimas ações do Instituto Cidade Democrática, bem como a proposta de um aplicativo prototipado no Laboratório de Inteligência Coletiva para Democracia, em Madri. Os autores consideram que os três dilemas da análise impactam sobremaneira o processo de autonomia e empoderamento dos cidadãos e são tão relevantes quanto construir arranjos de desenvolvimento em torno de tecnologias livres (PARRA FILHO; MARTINS, 2017).

No último Encontro Nacional de Pesquisa em Ciência da Informação (ENANCIB), em outubro de 2018, Gomes, Schneider e Bezerra (2018) apresentaram um trabalho que catalogou e analisou 18 aplicativos cívicos, que utilizaram dados de financiamento de campanhas eleitorais, no contexto da atuação política deles nos três poderes e sua repercussão midiática e informacional (GOMES; SCHNEIDER; BEZERRA, 2018). Um dos objetivos da pesquisa era entender de que modo esses aplicativos se apropriam dos dados abertos governamentais e como sua análise e categorização contribuem para a transparência política e a participação cidadã (GOMES; SCHNEIDER; BEZERRA, 2018). O resultado mostrou que a maior parte dos aplicativos cívicos analisados ainda trabalha com soluções proprietárias, contrastando com as pesquisas realizadas em outros países (GOMES; SCHNEIDER; BEZERRA, 2018).

\subsection{Análise de conteúdo}

Como é possível observar, a Ciência da Informação tem se feito presente nas discussões relativas a essa temática tão abrangente e atual que é a cidadania digital.

Dos onze trabalhos analisados, cinco deles Parra Filho e Martins (2017), Barros (2016), Cerquinho, Tavares e De Paula (2014), Azevedo (2012), Jambeiro, Sombreiro e Macambira (2011) e Santos (2011) se aproximam entre si quanto aos estudos de casos ou na apresentação de plataformas digitais específicas que promovem a participação social ou se apresentam como tais, no 
Brasil e no mundo. Já dois estudos, os de Ribeiro (2017) e Moreira (2015), fizeram um panorama, com abrangências e objetivos distintos, para buscar entender uma realidade, ora de participação política, ora do uso dos dados governamentais abertos, ambos num contexto de cidadania digital e democracia digital.

Também ficou claro que a maior parte dos estudos apresentados apontou para problemáticas que impactam diretamente no exercício da cidadania digital, dentre elas: a baixa qualidade informacional e governamental dos sites das capitais brasileiras como apresentado na pesquisa de Jambeiro, Sobreira e Macambira (2011); a falta de efetividade de dispositivos interativos dos websites de parlamentares, não garantindo que as demandas e sugestões dos cidadãos sejam respondidas pelo Governo, dissertado por Santos (2011); e também a consideração em duas pesquisas, Cerquinho, Tavares e De Paula (2014) e Ribeiro (2017), da possibilidade de plataformas governamentais estarem cercadas de um discurso de participação sem efeitos práticos, com pouca ou nenhuma influência no processo de decisão política, o que impacta diretamente na cidadania digital.

Por outro lado, foram apresentados no estudo de Moreira (2015), resultados que demonstraram a consolidação e a tendência de ampliação do uso dos DGA, apontando um modelo de governança caracterizado pelo envolvimento de atores estatais e não estatais, o que representa um grande avanço para a cidadania digital no Brasil. Já Gomes, Schneider e Bezerra (2018), adicionalmente pontuaram sobre a pouca reflexão com relação à utilização de aplicativos cívicos no Brasil, e como estudos sobre a construção de cada aplicativo e o acesso a eles podem trazer novas perspectivas para a cidadania digital.

O Quadro 1 apresenta o resumo dos objetivos, do ambiente de análise dos estudos, dos aspectos de cidadania digital analisados em cada pesquisa, bem como os resultados ou conclusões alcançados por cada uma. 
Sandryne Bernardino Barreto Januário, Renato Fernandes Correa

Quadro 1 - Resumo das contribuições da CI à cidadania digital no Brasil

\begin{tabular}{|c|c|c|c|c|}
\hline Artigo & Objetivo & $\begin{array}{l}\text { Ambiente } \\
\text { de análise }\end{array}$ & $\begin{array}{c}\text { Aspectos da } \\
\text { cidadania } \\
\text { digital }\end{array}$ & Resultados \\
\hline $\begin{array}{l}\text { Carvalho, } \\
\text { Santos } \\
(2009)\end{array}$ & $\begin{array}{l}\text { Explorar como se } \\
\text { processa a gestão } \\
\text { da informação em } \\
\text { órgãos ligados ao } \\
\text { governo federal. }\end{array}$ & $\begin{array}{l}\text { Órgãos do } \\
\text { Governo } \\
\text { Federal, } \\
\text { especialmente } \\
\text { nos } \\
\text { programas de } \\
\text { inclusão } \\
\text { digital }\end{array}$ & $\begin{array}{l}\text { Inclusão digital e } \\
\text { Participação } \\
\text { cívica }\end{array}$ & $\begin{array}{l}\text { As iniciativas } \\
\text { apresentadas são } \\
\text { importantes, mas não } \\
\text { suficientes para que todo } \\
\text { cidadão brasileiro tenha } \\
\text { oportunidades iguais. }\end{array}$ \\
\hline $\begin{array}{l}\text { Jambeiro, } \\
\text { Sobreira e } \\
\text { Macambira } \\
(2011)\end{array}$ & $\begin{array}{l}\text { Analisar os } \\
\text { Websites das } \\
\text { Câmaras de } \\
\text { Vereadores e } \\
\text { Prefeituras das } 26 \\
\text { Capitais dos } \\
\text { Estados } \\
\text { brasileiros, } \\
\text { visando verificar } \\
\text { se e como essas } \\
\text { plataformas } \\
\text { interagem com os } \\
\text { cidadãos. }\end{array}$ & $\begin{array}{l}\text { Websites das } \\
\text { Câmaras de } \\
\text { Vereadores e } \\
\text { Prefeituras } \\
\text { das } 26 \\
\text { Capitais dos } \\
\text { Estados } \\
\text { brasileiros }\end{array}$ & $\begin{array}{l}\text { Participação } \\
\text { política e } \\
\text { Acompanhamento } \\
\text { pelo eleitor }\end{array}$ & $\begin{array}{l}\text { As capitais estão longe de } \\
\text { aproveitar as } \\
\text { potencialidades que a } W e b \\
\text { oferece, uma vez que } \\
\text { possuem baixa qualidade } \\
\text { informacional nas três } \\
\text { variáveis selecionadas } \\
\text { para a análise. }\end{array}$ \\
\hline $\begin{array}{l}\text { Santos } \\
\text { (2011) }\end{array}$ & $\begin{array}{l}\text { Analisar as } \\
\text { condições de } \\
\text { participação } \\
\text { política nos sítios } \\
\text { parlamentares. }\end{array}$ & $\begin{array}{l}\text { Websites dos } \\
\text { deputados da } \\
\text { Assembleia } \\
\text { Legislativa da } \\
\text { Bahia }\end{array}$ & $\begin{array}{l}\text { Participação } \\
\text { política }\end{array}$ & $\begin{array}{l}\text { A disponibilidade de } \\
\text { dispositivos de } \\
\text { interatividade entre } \\
\text { Governo e os cidadãos não } \\
\text { garante que as demandas } \\
\text { sejam respondidas e as } \\
\text { sugestões efetivadas. }\end{array}$ \\
\hline $\begin{array}{l}\text { Azevedo } \\
(2012)\end{array}$ & $\begin{array}{l}\text { Apresentar a } \\
\text { experiência de } \\
\text { democracia } \\
\text { eletrônica do } \\
\text { partido Demoex. }\end{array}$ & $\begin{array}{l}\text { Site da } \\
\text { câmara } \\
\text { municipal de } \\
\text { Vallentuna, } \\
\text { na Suécia }\end{array}$ & $\begin{array}{l}\text { Participação } \\
\text { política }\end{array}$ & $\begin{array}{l}\text { Os espaços ou interfaces } \\
\text { de democracia digital e } \\
\text { transparência pública } \\
\text { precisam reconhecer e se } \\
\text { adaptar às necessidades e } \\
\text { particularidades do } \\
\text { cidadão. }\end{array}$ \\
\hline $\begin{array}{l}\text { Cerquinho, } \\
\text { Tavares e } \\
\text { De Paula } \\
(2014)\end{array}$ & $\begin{array}{l}\text { Analisar o Fórum } \\
\text { Eletrônico do } \\
\text { Estado de Minas } \\
\text { Gerais para } \\
\text { verificar se o } \\
\text { governo } \\
\text { concretizou as } \\
\text { proposições } \\
\text { virtuais. } \\
\end{array}$ & $\begin{array}{l}\text { Fórum } \\
\text { Eletrônico do } \\
\text { Estado de } \\
\text { Minas Gerais }\end{array}$ & $\begin{array}{l}\text { Participação } \\
\text { política }\end{array}$ & $\begin{array}{l}\text { Colocou em questão se o } \\
\text { governo está de fato } \\
\text { trabalhando em conjunto } \\
\text { com as pessoas ou se a } \\
\text { plataforma está cercada de } \\
\text { um discurso de } \\
\text { participação, sem efeitos } \\
\text { práticos. }\end{array}$ \\
\hline $\begin{array}{l}\text { Moreira } \\
(2015)\end{array}$ & $\begin{array}{l}\text { Traçar um } \\
\text { panorama sobre } \\
\text { como a sociedade } \\
\text { brasileira está } \\
\text { utilizando os } \\
\text { Dados } \\
\text { Governamentais }\end{array}$ & $\begin{array}{l}\text { Portal } \\
\text { Brasileiro de } \\
\text { Dados } \\
\text { Abertos, } \\
\text { Observatório } \\
\text { de Gestão da } \\
\text { Informação, }\end{array}$ & $\begin{array}{l}\text { Transparência, } \\
\text { Acesso à } \\
\text { informação, } \\
\text { Participação } \\
\text { cívica e } \\
\text { Acompanhamento }\end{array}$ & $\begin{array}{l}\text { Demonstrou-se a } \\
\text { consolidação e a tendência } \\
\text { de ampliação do uso dos } \\
\text { DGA, apontando um } \\
\text { modelo de governança } \\
\text { caracterizado pelo } \\
\text { envolvimento de atores }\end{array}$ \\
\hline
\end{tabular}




\begin{tabular}{|c|c|c|c|c|}
\hline & $\begin{array}{l}\text { Abertos (DGA), a } \\
\text { partir do estudo } \\
\text { dos aplicativos } \\
\text { gerados. }\end{array}$ & $\begin{array}{l}\text { Alertas } \\
\text { Google }\end{array}$ & & $\begin{array}{l}\text { estatais e não estatais, pela } \\
\text { efetiva utilização das TIC. }\end{array}$ \\
\hline $\begin{array}{l}\text { Brisola } \\
(2016)\end{array}$ & $\begin{array}{l}\text { Pensar em como } \\
\text { despertar o gosto } \\
\text { pela informação e } \\
\text { pela construção } \\
\text { do conhecimento } \\
\text { a fim de estimular } \\
\text { o exercício de } \\
\text { uma cidadania } \\
\text { participativa. }\end{array}$ & Ágora Digital & $\begin{array}{l}\text { Participação } \\
\text { cívica, } \\
\text { Formação do } \\
\text { cidadão. }\end{array}$ & $\begin{array}{l}\text { É de responsabilidade da } \\
\text { CI colaborar com a } \\
\text { formação do } \\
\text { conhecimento no cidadão } \\
\text { que convive neste } \\
\text { cibermundo } \\
\text { contemporâneo. }\end{array}$ \\
\hline $\begin{array}{l}\text { Barros } \\
(2016)\end{array}$ & $\begin{array}{l}\text { Avaliar, a partir } \\
\text { de critérios da } \\
\text { literatura de } \\
\text { democracia } \\
\text { digital, como as } \\
\text { características das } \\
\text { plataformas } \\
\text { modelaram o } \\
\text { processo de } \\
\text { participação e } \\
\text { quais lições } \\
\text { poderiam ser } \\
\text { aprendidas com } \\
\text { esse processo. }\end{array}$ & $\begin{array}{l}\text { Três } \\
\text { plataformas } \\
\text { de consulta } \\
\text { pública que } \\
\text { foram } \\
\text { desenvolvidas } \\
\text { durante o } \\
\text { processo de } \\
\text { elaboração do } \\
\text { Marco Civil } \\
\text { da Internet } \\
\text { (MCI) }\end{array}$ & $\begin{array}{l}\text { Participação } \\
\text { cívica, } \\
\text { Inclusão social }\end{array}$ & $\begin{array}{l}\text { Falta um procedimento } \\
\text { padrão para consulta } \\
\text { pública, o que torna o } \\
\text { mecanismo vulnerável à } \\
\text { vontade dos gestores e } \\
\text { potencialmente alvo de } \\
\text { desconfiança por parte do } \\
\text { público, e que a } \\
\text { padronização das } \\
\text { consultas poderia } \\
\text { beneficiar o governo e a } \\
\text { sociedade. }\end{array}$ \\
\hline $\begin{array}{l}\text { Ribeiro } \\
\text { (2017) }\end{array}$ & $\begin{array}{l}\text { Identificar o } \\
\text { estado da arte } \\
\text { sobre a } \\
\text { participação } \\
\text { política e } \\
\text { aprofundar o } \\
\text { tema por meio de } \\
\text { casos de } \\
\text { iniciativas online } \\
\text { criadas para } \\
\text { permitir e/ou } \\
\text { estimular a } \\
\text { participação do } \\
\text { cidadão nas } \\
\text { questões } \\
\text { políticas, no } \\
\text { Brasil e no } \\
\text { mundo. }\end{array}$ & $\begin{array}{l}\text { Bases de } \\
\text { dados Web of } \\
\text { Science, } \\
\text { Scopus e } \\
\text { DOAJ }\end{array}$ & $\begin{array}{l}\text { Participação } \\
\text { política }\end{array}$ & $\begin{array}{l}\text { A maioria das plataformas } \\
\text { online de participação } \\
\text { política é representada por } \\
\text { portais governamentais } \\
\text { que promovem um fluxo } \\
\text { de informação com } \\
\text { alguma possibilidade de } \\
\text { interação e discussão entre } \\
\text { cidadãos e governantes, } \\
\text { mas pouca ou nenhuma } \\
\text { influência no processo de } \\
\text { decisão política, } \\
\text { especialmente nos casos } \\
\text { do Brasil. }\end{array}$ \\
\hline $\begin{array}{l}\text { Parra Filho } \\
\text { e Martins } \\
\text { (2017) }\end{array}$ & $\begin{array}{l}\text { Realizar um } \\
\text { balanço do } \\
\text { cenário do uso de } \\
\text { tecnologias por } \\
\text { parte dos } \\
\text { governos, } \\
\text { especialmente } \\
\text { quanto às } \\
\text { inovações } \\
\text { produzidas na } \\
\text { última década no } \\
\text { Poder Executivo }\end{array}$ & $\begin{array}{l}\text { A análise } \\
\text { dessas } \\
\text { inovações em } \\
\text { torno de três } \\
\text { dilemas: a } \\
\text { inclusão } \\
\text { digital, a } \\
\text { manipulação } \\
\text { política e a } \\
\text { governança } \\
\text { digital. }\end{array}$ & $\begin{array}{l}\text { Inclusão digital } \\
\text { Participação } \\
\text { política } \\
\text { Governança } \\
\text { digital }\end{array}$ & $\begin{array}{l}\text { Os três dilemas da análise } \\
\text { impactam sobremaneira o } \\
\text { processo de autonomia e } \\
\text { empoderamento dos } \\
\text { cidadãos e são tão } \\
\text { relevantes quanto } \\
\text { construir arranjos de } \\
\text { desenvolvimento em torno } \\
\text { de tecnologias livres. }\end{array}$ \\
\hline
\end{tabular}


Contribuições da Ciência da Informação para a cidadania digital no Brasil: a participação social em questão

Sandryne Bernardino Barreto Januário, Renato Fernandes Correa

\begin{tabular}{|c|c|c|c|c|}
\hline & Federal brasileiro. & & & \\
\hline $\begin{array}{l}\text { Gomes, } \\
\text { Schneider } \\
\text { e Bezerra } \\
(2018)\end{array}$ & $\begin{array}{l}\text { Entender de que } \\
\text { modo os } \\
\text { aplicativos } \\
\text { cívicos se } \\
\text { apropriam dos } \\
\text { dados abertos } \\
\text { governamentais e } \\
\text { como sua análise } \\
\text { e categorização } \\
\text { contribuem para a } \\
\text { transparência } \\
\text { política e a } \\
\text { participação } \\
\text { cidadã. }\end{array}$ & $\begin{array}{l}\text { Aplicativos } \\
\text { cívicos que } \\
\text { utilizaram } \\
\text { dados de } \\
\text { financiamento } \\
\text { de campanhas } \\
\text { eleitorais. }\end{array}$ & $\begin{array}{l}\text { Transparência, } \\
\text { Participação } \\
\text { cívica }\end{array}$ & $\begin{array}{l}\text { A maior parte dos } \\
\text { aplicativos cívicos } \\
\text { analisados ainda trabalha } \\
\text { com soluções } \\
\text { proprietárias, contrastando } \\
\text { com as pesquisas } \\
\text { realizadas em outros } \\
\text { países. }\end{array}$ \\
\hline
\end{tabular}

Fonte: Elaborado pelos autores.

A partir do Quadro 1 é possível perceber um cenário diversificado das publicações sobre cidadania digital no Brasil. Quanto aos ambientes digitais analisados pelos estudos, identificaram-se sites, aplicativos e bases de dados, de natureza pública ou privada. Foram diversos também os objetivos, mas especialmente voltados para a participação dos cidadãos em meio digital. Quanto aos aspectos de cidadania digital identificados, a participação social foi a ferramenta comum a todos os estudos, seguida da inclusão digital e da transparência, ambas presentes em dois estudos dos onze analisados. Quanto aos resultados, observou-se que a maior parte das pesquisas apontou problemáticas que impactam diretamente no exercício da cidadania digital. Isso porque, segundo os pesquisadores, parte das iniciativas nesse tema está cercada de um discurso de participação sem efeitos práticos, com pouca ou nenhuma influência no processo de decisão política. Por outro lado, também foram apresentados estudos na CI que demonstraram a consolidação e a tendência do uso dos DGA para um novo modelo de governança digital, o que representa um grande avanço para a cidadania digital no Brasil.

A convergência entre os temas cidadania digital e participação social tem despertado interesse e vem sendo investigada pela CI brasileira. Também corrobora com esta observação a publicação em 2017 de um livro dedicado à participação social, utilizando-se da expressão protagonismo social (GOMES; NOVO, 2017). O livro teve como objetivo compreender o uso da informação 
enquanto fenômeno que emerge das relações sociais, especialmente em questões culturais, de memória e relacionadas às políticas públicas.

Para Moura (2017), o protagonismo revela a centralidade e a “[...] pertinência da participação social de sujeitos identificados com a ação coletiva necessária à transformação social e à construção da história.” (MOURA, 2017, p. 93). Num contexto contemporâneo, o conceito do protagonismo envolve aspectos políticos, socioculturais e tecnológicos, diversificando-se e se expandindo a diferentes cenários. Ainda segundo a pesquisadora, acredita-se que o empoderamento sociocultural de diferentes atores sociais na condição de protagonistas de suas histórias e narrativas pode contribuir na compreensão plural de identidade e apoiar a consolidação de espaços públicos de convivência e compartilhamento mais identificados com visões de mundo que, para além dos artificialismos humanos, fortaleçam a memória comum (MOURA, 2017).

\section{Considerações finais}

A Ciência da Informação tem pesquisado a temática cidadania digital, uma vez que a informação é requisito e meio para seu exercício, bem como um fenômeno oriundo do dinamismo da evolução da sociedade e das suas demandas informacionais. A interdisciplinaridade, o caráter social e o viés tecnológico permitem que a CI atue em conjunto com as mais diversas áreas do conhecimento e contribua com o desenvolvimento de temáticas importantes, tais como a cidadania digital.

Como foi possível perceber nos trabalhos analisados, a CI se apresenta interessada e atuante nas discussões acerca da cidadania digital, especialmente quanto ao fluxo da informação na participação e interação do cidadão com a administração pública em ambientes digitais, nas mais diversas plataformas.

A partir da análise dos resultados, concluiu-se que as publicações sobre a cidadania digital no Brasil, na perspectiva da participação social, apresentam-se num cenário diversificado. Identificaram-se sites, aplicativos, bases de dados, públicos e privados, com os mais diversos objetivos e aspectos de cidadania digital, mas a participação social foi a ferramenta comum a todos os estudos. 
Observou-se também que a maior parte dos estudos apontou problemáticas que impactam na cidadania digital, uma vez que parte das iniciativas não possui efeitos práticos, ou seja, tem pouca ou nenhuma influência no processo de decisão política. Entretanto, também foram apresentadas pesquisas na CI que demonstraram os benefícios do uso dos DGA para um novo modelo de governança digital, o que representa um grande avanço para a cidadania digital no Brasil.

É nesse contexto que se entende que o direito de acessar a informação, temática tão discutida nos últimos anos na CI, é de extrema importância, mas não é mais o suficiente; continua sendo o princípio, porém não é mais o fim.

O cidadão quer participar e ser protagonista do exercício da sua cidadania, inclusive no meio digital, e contribuir com o seu bairro, sua cidade, seu estado ou seu país. Essa participação está diretamente relacionada à construção de uma memória coletiva, crítica e engajada na formação de novas políticas públicas e novas diretrizes para o país.

Quanto às limitações deste trabalho, o quantitativo reduzido de pesquisas na área da CI no Brasil sobre a temática cidadania digital foi um fator limitante. Não houve dificuldade em localizar estudos mais gerais, como por exemplo, sobre o governo eletrônico e a própria Lei de Acesso a Informação (LAI), mas sobre a cidadania digital com a perspectiva de participação social, poucos foram os estudos encontrados.

Como trabalhos futuros, uma pesquisa sobre os aplicativos móveis desenvolvidos visando a promoção da cidadania digital, traçar o perfil dos cidadãos que utilizam tais plataformas digitais, bem como a análise do conteúdo das informações produzidas por eles em tais plataformas, podem contribuir para o entendimento e desenvolvimento da cidadania digital no Brasil.

Outra linha de trabalhos futuros contempla o estudo da usabilidade dos aplicativos móveis, visando a identificação de pontos fortes e fracos que interferem no exercício da cidadania por meio dessas plataformas. A experiência do cidadão ao utilizar uma plataforma digital voltada para a cidadania pode comprometer o seu engajamento cívico, uma vez que problemas de navegação, 
checkouts burocráticos (cadastros extensos para usar o aplicativo), design, entre outros, desestimulam o usuário a permanecer no sistema.

Assim, espera-se que o Brasil, em todas as esferas, acompanhe as tendências de governança digital cada vez mais adotadas em todo o mundo e acolha essa demanda de participação social em meio digital com seriedade e efetividade, afinal isso não é um favor, é um direito do cidadão exercer a sua cidadania digital.

\section{Referências}

ARAÚJO, A. M. de; CARDOSO, A. M. P. Pode o governo eletrônico contribuir para a promoção da cidadania? a busca de melhor compreensão a partir do estudo de uso dos websites municipais. In: ENCONTRO NACIONAL DE PESQUISA EM CIÊNCIA DA INFORMAÇÃO, 7., 2006, São Paulo. Anais [...]. São Paulo: UNESP, 2006.

ARAÚJO, C. A. Á. A Ciência da Informação como ciência social. Ciência da Informação, Brasília, v. 32, n. 3, p. 21-27, 2003.

AZEVEDO, M. M. V. de. Algumas considerações acerca de uma democracia direta eletrônica. DataGramaZero, João Pessoa, v. 13, n. 4, p. 1-12, 2012.

BARROS, S. Os desafios das consultas públicas online: lições do marco civil da Internet. Liinc em revista, Rio de Janeiro, v. 12, n. 1, p. 72-89, 2016.

BRISOLA, A. C. A. S. A ágora digital, a competência crítica em informação e a cidadania ampliada: uma construção possível. 2016. Dissertação (Mestrado em Ciência da Informação) - Programa de Pós-Graduação em Ciência da Informação, Universidade Federal do Rio de Janeiro, Rio de Janeiro. 2016.

CARVALHO, A. M. G. de; SANTOS, P. L. V. A. C. Cidadania digital e a distribuição da informação nos projetos governamentais. In: ENCONTRO NACIONAL DE PESQUISA EM CIÊNCIA DA INFORMAÇÃO, 10., 2009, João Pessoa. Anais [...]. João Pessoa: ANCIB, 2009.

CARVALHO, A. M. G. de; AMÉRICO, M. Inclusão e Cidadania Digital no Brasil: a (des) articulação das políticas públicas. Redes.com, Sevilha, v. 1, p. 69-84, 2014.

CARVALHO, J. M. de. Cidadania no Brasil: o longo caminho. Rio de Janeiro: Civilização brasileira, 2008.

CASTELLS, M. The Internet galaxy, reflections on the Internet, business and society. Oxford: Oxford University Press, 2001. 
CERQUINHO, K. G.; TAVARES, W.; DE PAULA, A. P. P. Movimento minas: a participação cidadã via Internet no estado de minas gerais. Perspectivas em Gestão \& Conhecimento, João Pessoa, v. 4, n. 1, p. 218-236, 2014.

CUNHA, M. A. V. C. da; MIRANDA, P. R. de M. O uso de TIC pelos governos: uma proposta de agenda de pesquisa a partir da produção acadêmica e da prática nacional. Organizações \& Sociedade, Salvador, v. 20, n. 66, p. 543566, 2013.

FRADE, M. A. F. Mídia e cidadania. Informação \& Sociedade, João Pessoa, v. 12, n. 1, p. 1-17, 2002.

GARCIA, J. C. R.; TARGINO, M. das G.; DANTAS, E. R. F. Conceito de responsabilidade social da Ciência da Informação. Informação \& Informação, Londrina, v. 17, n. 1, p. 1-25, 2012.

GOMES, H. F.; NOVO, H. F. (org.). Informação e protagonismo social. Salvador: EDUFBA, 2017.

GOMES, J. C.; SCHNEIDER, M. A. F.; BEZERRA, A. C. Aplicativos Cívicos: apropriação de dados abertos governamentais pela sociedade. In: ENCONTRO NACIONAL DE PESQUISA EM CIÊNCIA DA INFORMAÇÃO, 19., 2018, Londrina. Anais [...]. Londrina: ANCIB, 2018. p. 3153-3167.

GOMES, W. A Democracia digital e o problema da participação civil na decisão política. Fronteiras, São Leopoldo, v. 7, n. 3, p. 214-222, 2005.

JAMBEIRO, O.; SOBREIRA, R.; MACAMBIRA, L. Informação, participação cívica e controle da gestão pública: análise dos websites das capitais brasileiras. In: ENCONTRO NACIONAL DE PESQUISA EM CIÊNCIA DA INFORMAÇÃO, 12., 2011, Brasília. Anais [...]. Brasília: UnB, 2011. p. 1-28.

LÉVY, P. Ciberdemocracia. Lisboa: Instituto Piaget, 2002.

MAIA, R. C. M. Democracia e a Internet como esfera pública virtual: aproximação às condições da deliberação. In: GOMES, W.; MAIA, R. C.M. Comunicação e democracia: problemas e perspectivas. São Paulo: Paulus, 2008, p.277-292.

MOREIRA, D. L. J. Panorama sobre a utilização de dados governamentais abertos no Brasil: um estudo a partir dos aplicativos desenvolvidos. 2015. Dissertação (Mestrado em Ciência da Informação) - Programa de Pós-graduação em Ciência da Informação, Universidade Federal do Rio de Janeiro, Rio de Janeiro, 2015. 
MOURA, M. A. Narrativas culturais, protagonismo e mundo comum. In: GOMES, Henriette Ferreira; NOVO, Hildenise Ferreira (org.). Informação e protagonismo social. Salvador: EDUFBA, 2017. p. 93-108.

PARRA FILHO, H. C. P.; MARTINS, R. A. P. Governança digital como vetor para uma nova geração de tecnologias de participação social no brasil. Liinc em revista, Rio de Janeiro, v. 13, n. 1, p. 223-236, 2017.

RIBEIRO, C. A. Governança Informacional na reforma do Estado: estudo exploratório sobre política pública de acesso à informação governamental. 2003. Dissertação (Mestrado em Ciência da Informação) - Escola de Ciência da Informação, Universidade Federal de Minas Gerais, Belo Horizonte, 2003.

RIBEIRO, H. C. L. Participação política a partir de iniciativas online: possibilidades, limites e desafios para a democracia. 2017. Dissertação (Mestrado em Ciência da Informação) - Programa de Pós-graduação em Ciência da Informação, Universidade Federal do Rio de Janeiro, Rio de Janeiro, 2017.

ROCHA, M. P. C. A questão cidadania na sociedade da informação. Ciência da Informação, Brasília, v. 29, n. 1, p. 40-45, 2000.

SANTOS, J. C. Informação pública e participação política em rede: uma análise da governança eletrônica nos websites dos deputados do Estado da Bahia. 2011. Dissertação (Mestrado em Ciência da Informação) - Programa de Pós-Graduação em Ciência da Informação, Universidade Federal da Bahia, Salvador, 2011.

SANTOS, J. C. S. Informação, democracia digital e participação política: uma breve revisão teórico-analítica. Em questão, Porto Alegre, v. 19, n. 2, p. 195216, 2013.

VEDEL, T. L'Idée de democratie electronic: origines, visions, questions. In. PASCAL, Perrineau. Le Désenchantement démocratique. La Tour d'Aigues: Editions de 1'Aube, 2003. p. 243-266.

\title{
Contributions of Information Science to digital citizenship in Brazil: the social participation in question
}

\begin{abstract}
This work features survey and discussion of Brazilian work about digital citizenship in the field of information science, with a focus on the social participation. It's an exploratory and descriptive, bibliographical research conducted through content analysis of the selected publications. From the literature research were raised eleven works published in the last ten years in scientific journals, academic events or graduate programs in information
\end{abstract}


science, directly related to the subject in question. Objects, goals and contributions of each work are synthesized and presented. Then, it presents and discusses a framework with the summary of studies, including aspects of digital citizenship identified in each job. As a result, it was observed that most of the research pointed problems which impact directly on the exercise of citizenship. That's because, according to the researchers, part of the initiatives in this theme is surrounded by a speech of participation with no practical effects, with little or no influence on the political decision-making process. On the other hand, were also presented studies that demonstrated the consolidation and the trend of the use of open government data for a new model of digital governance, which represents a major breakthrough for digital citizenship in Brazil.

Keywords: Digital citizenship. Social participation. Information science. Brazil.

Recebido: 28/06/2019

Aceito: $21 / 10 / 2019$ 